\title{
ANÁLISE DA DINÂMICA TERRITORIAL DA PESCA NO MÉDIO ARAGUARI: O CASO DE FERREIRA GOMES (AP/BRASIL)
}

Thallys Arimar Lopes Rosa

Universidade Federal do Amapá thallys.nr@gmail.com

Ricardo Angelo Pereira de Lima

Universidade Federal do Amapá

ricardoangelo pereira@yahoo.es

\section{RESUMO}

A energia gerada por meio das Usinas Hidroelétricas de Energia (UHE), se consolidou como uma importante fonte no abastecimento energético, voltado para o desenvolvimento do Brasil. No entanto, o processo de implantação e operação desses empreendimentos tem produzido ao ambiente físico e social, uma série de impactos que agem especialmente nos territórios das comunidades locais. Essa fronteira energética encontrou na bacia do Rio Araguari, no estado do Amapá, um espaço favorável para seu desenvolvimento e expansão. Visto isso, este estudo realiza uma análise das dinâmicas territoriais da atividade de pesca, utilizando como recorte espacial o município de Ferreira Gomes. Metodologicamente se empregou as técnicas de pesquisa bibliográfica e, em campo, de grupo focal e mapeamento participativo. Os resultados obtidos revelaram que a pesca realizada no médio Araguari é fundamentalmente artesanal. Os pescadores locais têm no pescado a principal fonte de alimentação e renda. Anteriormente a implantação das UHE, a atividade tinha, nos rios e igarapés próximos, uma fonte abundante de recurso. Porém, as modificações no ambiente físico produzidas pelos empreendimentos, impuseram ao pescador a busca de novas estratégias territoriais de pesca, visto a fragilização dos territórios socialmente construídos e a diminuição da sua base produtiva.

Palavras-chave: Amazônia. Hidroeletricidade. Impactos socioambientais. Pesca Artesanal. Rio Araguari.

\section{ANALYSIS OF FISHERIES TERRITORIAL DYNAMICS IN THE MIDDLE ARAGUARI: THE CASE OF FERREIRA GOMES (AP/BRASIL)}

\begin{abstract}
The energy generated through the Hydroelectric Power Plants (HPP) has consolidated itself as an important source of energy supply, focused on the development of Brazil. However, the process of implanting and operating these enterprises has produced a series of impacts on the physical and social environment, which act especially in the territories of local communities. This energetic frontier found in the Araguari River basin, in the state of Amapá, a favorable space for its development and expansion. In view of this, this study performs an analysis of the territorial dynamics of fishing activity, using the municipality of Ferreira Gomes as a spatial outline. Methodologically, bibliographic research and, in the field, focus group and participatory mapping techniques were used. The results obtained revealed that the fishing carried out in the Middle Araguari is fundamentally artisanal. Local fishermen have fish as the main source of food and income. Prior to the implantation of the HPP, the activity had, in the rivers and nearby streams, an abundant source of resources. However, the changes in the physical environment produced by the enterprises, imposed on the fisherman the search for new territorial fishing strategies, given the fragility of the socially constructed territories and the reduction of their productive base.
\end{abstract}

Keywords: Amazon. Hydroelectricity. Socio-environmental impacts. Artisanal Fishing. Rio Araguari. 


\section{INTRODUÇÃO}

O território brasileiro possui uma ampla e diversa malha hídrica. Essa característica tem possibilitado a diversos extratos da sociedade o uso desse bem natural como recurso. Se destaca nesse contexto a pesca praticada de maneira artesanal, uma vez que é uma das mais antigas atividades realizadas e que historicamente vem construindo sociedades (DIEGUES, 2003; 2004).

A pesca artesanal alcança múltiplas camadas sociais e atua como vetor econômico em diferentes escalas, isso pode proporcionar desde o desenvolvimento e/ou manutenção de pequenas comunidades locais até o progresso econômico regional. A estática pesqueira realizada pelo Instituto Brasileiro do Meio Ambiente e dos Recursos Naturais Renováveis (IBAMA), do ano de 2007, traduz um pouco desse contexto, quando relata que a pesca artesanal é responsável por pouco mais de $80 \%$ das capturas no país. Entretanto, esse movimento tem se deparado, nas últimas décadas - com chegada de outra atividade que também tem a água como o seu recurso básico.

A geração de energia por meio do potencial da gravidade da água, tem se consolidado como uma importante base da produção energética brasileira. Nesse sentido, foi encontrado nas UHE o meio necessário para a produção dessa modalidade de energia em larga escala. Segundo a Agência Nacional de Energia Elétrica (ANEEL) (2005), uma UHE é constituída por: um sistema de captação e adução de água; uma barragem; casa de força e vertedouro. Essas estruturas trabalham em conjunto, onde a barragem tem a função de interromper o curso normal da água, o que cria um reservatório. Esse reservatório, além de armazenar água, permite que a vazão dos rios seja controlada, tanto em períodos chuvosos, quanto de estiagem.

O Brasil teve nos estados de Minas Gerais e São Paulo os primeiros aproveitamentos hídricos visando à geração de energia, ainda no fim do século XIX, porém somente em meados da década de 1950, com o processo acelerado da industrialização, as UHE despontaram na configuração nacional como melhor e mais viável maneira de produzir energia em grande escala e, ainda, como uma forma de levar o desenvolvimento às regiões em que são instaladas.

Todavia, mais da metade das UHE estão localizadas na Amazônia. Segundo Bermman (2007), esses empreendimentos vêm produzindo elevados impactos nas dimensões sociais e ambientais, decorrentes de sua implantação e operação. No Amapá, essa frente encontrou na bacia do Rio Araguari um ambiente favorável, visto o potencial hidráulico do seu curso principal. Entretanto, a dinâmica imposta por esses empreendimentos tem desestruturado as atividades locais preexistentes, em especial a de pesca.

Assim, centralmente, se objetivou analisar as novas dinâmicas pesqueiras e de organização do território a partir da implantação dos grandes empreendimentos hidroelétricos no município de Ferreira Gomes.

A importância para a execução desta pesquisa se encontra no fato de que implantação e operação de um grande empreendimento hidroelétrico, produz uma série de dinâmicas que se manifestam no ambiente físico e social; gerando tanto impactos negativos quanto positivos. Pode-se apontar como negativo: a perda de espécies de plantas e animais; modificações na morfologia do rio; perda de solos; translocação da população; alterações na pesca e a aquicultura (JUNK; MELLO, 1990; SOUSA, 2000).

Todavia, as experiências de hidroeletricidade descritas na Amazônia brasileira, encontradas nos trabalhos de Santos (1995); Pinto (2002); De Francesco e Carneiro (2015); e, mais especificadamente no estado do Amapá, em Campos (2016) e Corrêa e Porto (2017), relatam que esses processos geram impactos de ordem ambiental, social e econômica, que atuam também na dimensão territorial, causando desestruturação e desorganização.

\section{METODOLOGIA}

\section{Área de estudo}

O município de Ferreira Gomes (Figura 01) se situa nas coordenadas geográficas $00^{\circ} 51^{\prime} 17^{\prime \prime} \mathrm{N}$ (Latitude) e 51010'25" W (Longitude); possui uma área de 4.973,852 $\mathrm{km}^{2}$ e ocupa aproximadamente $3,5 \%$ do total territorial do estado do Amapá. Limita-se com os municípios de Pracuúba e Amapá (ao norte), Porto Grande (ao sul), Tartarugalzinho e Cutias (ao leste), Porto Grande e Serra do Navio (ao oeste). É distante $137 \mathrm{~km}$ da capital, Macapá, e tem sua sede localizada as margens do Rio Araguari. 
O Rio Araguari, por sua vez, possui uma extensão aproximada de $498 \mathrm{~km}$, sendo ele dividido em três trechos: Curso Superior ou Alto Araguari (132 km); Curso Médio ou Médio Araguari (161 km), onde se encontra implantada a UHE de Coaracy Nunes (UHECN), UHE Cachoeira Caldeirão (UHECC) e a UHE Ferreira Gomes (UHEFG); e Curso Inferior ou Baixo Araguari (205 km), que é a parte do rio onde ocorrem os menores índices de declividade (PROVAM, 1990).

Figura1 - Ferreira Gomes (AP): Localização da área de estudo, 2020.

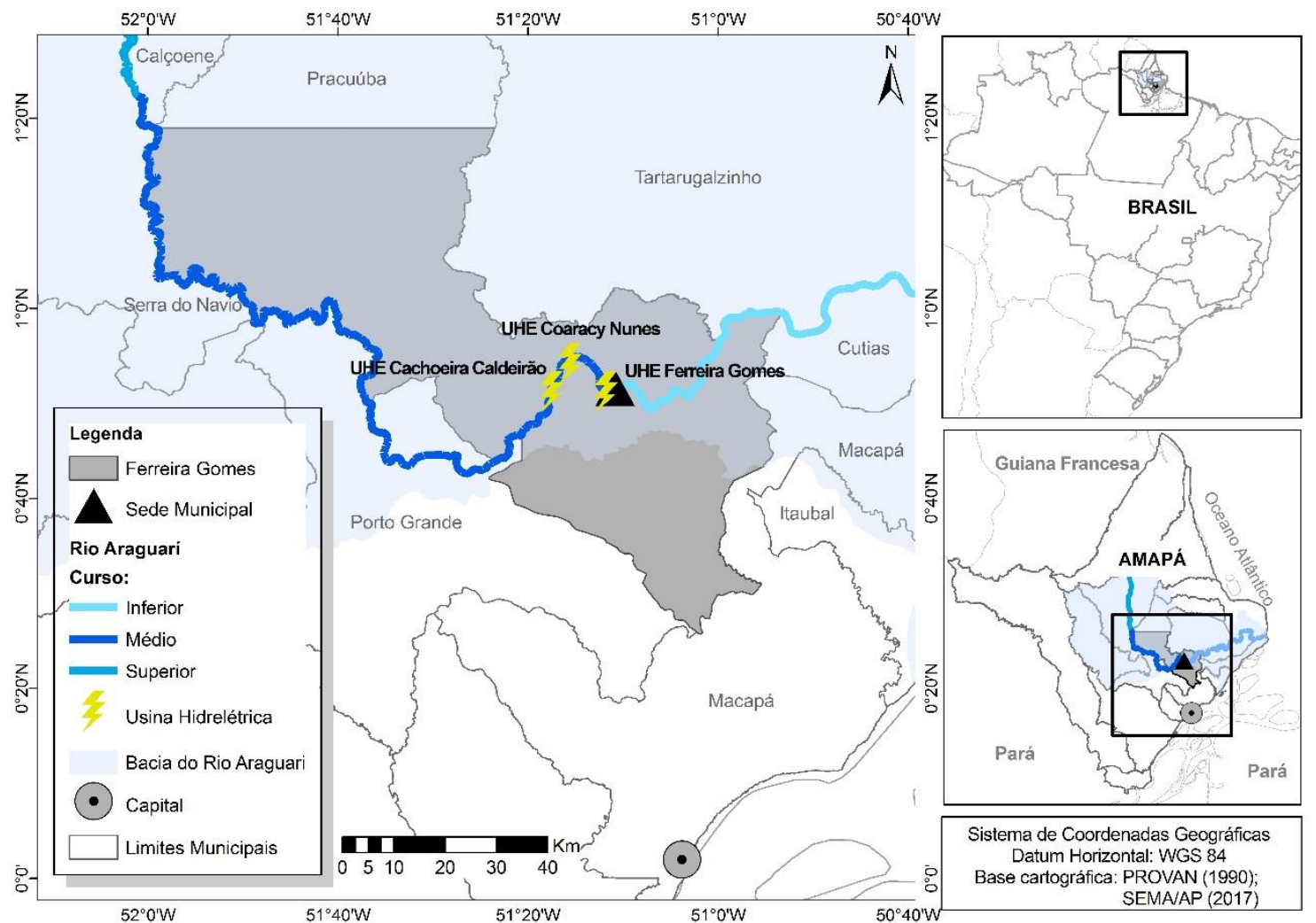

Fonte - Elaborado pelos autores (2019).

\section{Os caminhos em campo: desafios, limitações e técnicas}

O trabalho de campo apresenta a possibilidade de ir além de uma mera aproximação com aquilo que desejamos conhecer e estudar, mas de criar conhecimento, partindo das diferentes realidades presentes no campo (CRUZ NETO, 1994). Para isso, se recorreu a tentativa de superação da pesquisa vista tão somente como o uso de instrumentos de coleta de informações visando dar conta de seus objetivos, para uma perspectiva de maior diálogo com as realidades locais, mas não deixando de lado os cuidados teórico-metodológicos inerentes a ciência.

O campo de pesquisa é o recorte que o pesquisador faz em termos de espaço (MINAYO, 1992), nele estão realidades empíricas a serem estudadas a partir das concepções teóricas que fundamentam o objeto da investigação (CRUZ NETO, 1994). Partindo dessa percepção e remontando ao objeto e objetivo desse estudo em uma visão ampla, algumas questões surgem: onde é o espaço da pesca? Onde termina e onde começa suas dinâmicas? A primeira resposta poderia ser: a água, o lago, o rio, o mar... Esse entendimento em suma, mesmo que de forma superficial, traz uma visão válida ao debate, entretanto, desconsidera o caráter sistemático desses ambientes, visto que são conectados a outros sistemas e há uma infinidade de complexas estruturas naturais e sociais.

Dúvidas como essas se desdobram em desafios de objetividade metodológica para a pesquisa, em especial a social (MINAYO, 1992; 2001). Na atividade de pesca, o "onde" desagua em questões mais profundas do que somente as espaciais. Há uma conjuntura de elementos culturais, econômicos, naturais e institucionais presentes e que servem de base para as possibilidades (ou não) de escolha 
do pescador. São esses elementos que auxiliaram no recorte formal do estudo, mesmo entendendo de antemão, que ele não alcança a totalidade das dinâmicas produzidas pela atividade.

Atendendo as considerações, apontamentos teóricos e dada as limitações, o locus escolhido para o desenvolvimento da pesquisa foi o Rio Araguari, mais precisamente o seu trecho médio que percorre os municípios de Ferreira Gomes (já caracterizados anteriormente). A escolha do local se deu pelas novas dinâmicas de organização, adaptação e estruturação que a implantação das Hidroelétricas, Coaracy Nunes, Ferreira Gomes e Cachoeira Caldeirão, imprimiram à atividade territorial da pesca.

Foram realizadas três idas a campo, entre outubro de 2018 e janeiro de 2019 , onde as atividades foram desenvolvidas (Quadro 1). A escolha pela data teve como parâmetro o período de defeso, que no estado ocorreu entre 15 de novembro de 2018 a 15 de março de 2019, fator que favoreceria o contato com os pescadores na sede dos municípios.

Quadro 1 - Ferreira Gomes (AP): Trabalhos de campo, 2019.

\begin{tabular}{|c|c|}
\hline Data & Atividade \\
\hline $29 / 10 / 2018$ & Observação e visita à colônia de pescadores \\
\hline $10 / 01 / 2019$ & Grupo focal \\
\hline $18 / 01 / 2019$ & Mapeamento participativo \\
\hline
\end{tabular}

Fonte - Elaborado pelos autores (2019).

\section{O grupo focal:}

O grupo focal se mostrou como a técnica que melhor se ajustaria a realidade logística da pesca local, visto que os pescadores em geral exercem suas atividades de maneira individual ou familiar, com pescarias que não atendem a um cronograma formal. A participação das colônias, neste sentido, mostrou-se essencial no que diz respeito ao convite dos pescadores para a pesquisa e na disponibilização da sede para a aplicação.

A técnica visa compreender o processo de construção das percepções, atitudes e representações sociais locais por meio da coleta de dado através das interações grupais ao se discutir um tópico especial sugerido pelo pesquisador (DEBUS, 1997; GONDIM, 2003). O grupo focal teve como função resgatar as características do ambiente e da atividade pesqueira antes e depois da implantação das hidroelétricas de Cachoeira Caldeirão e Ferreira Gomes, buscando identificar as principais transformações na maneira de se pescar, nos ambientes de pesca, na organização espacial dos pescadores e no gerenciamento econômico da atividade pesqueira.

A realização do primeiro grupo focal ocorreu em Ferreira Gomes, no dia 10 de janeiro de 2019, na sede da colônia dos pescadores (Figura 2). O grupo contou com a participação direta de nove pescadores e durou 50 minutos.

Figura 2 - Ferreira Gomes (AP): Aplicação do grupo focal, 2019.

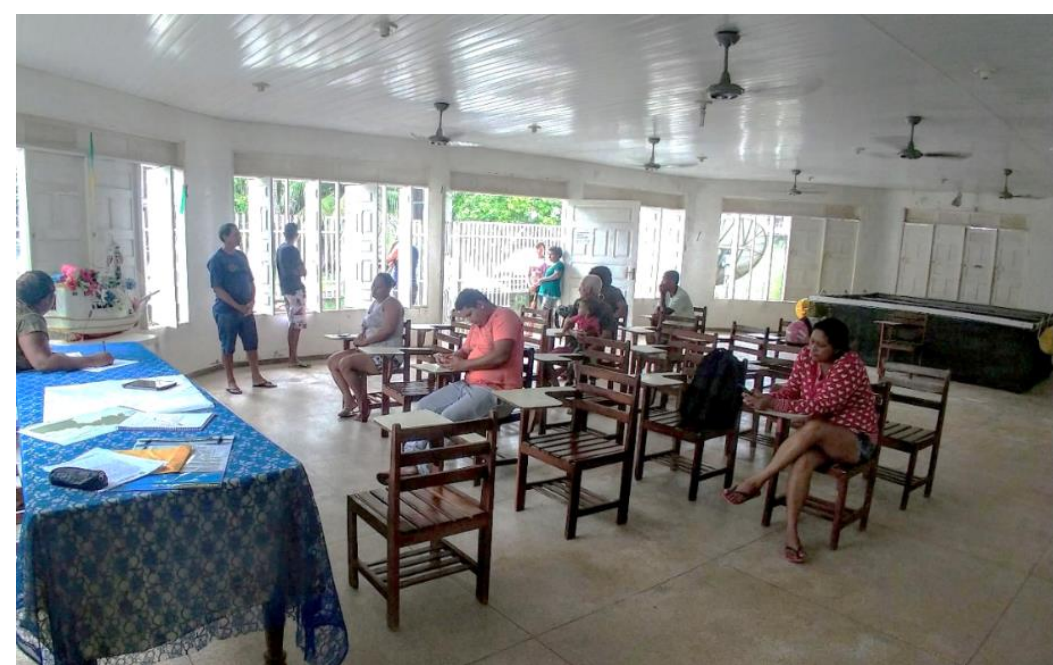

Fonte - Autores (2019) 
A proposta do grupo focal foi apresentada e aprovada pelo Comitê de Ética em Pesquisa (CEP UNIFAP), sob o parecer de $n^{\circ}$ 2.925.813. A formalização do aceite dos pescadores na pesquisa se deu por meio da assinatura de um Termo de Consentimento Livre e Esclarecido (TCLE), que apresentou os objetivos do trabalho e descreveu o processo metodológico.

Assim, por volta de 10h, o grupo iniciou seguindo a sequência dos temas e questões-chave descritas no roteiro de aplicação, construído com base nas experiências empíricas em relatos de casos semelhantes na literatura.

\section{O mapeamento participativo}

O mapeamento participativo dos locais de pesca (BEGOSSI, 2004; SILVA, 2008; CHAVES, 2011) compôs a terceira fase do campo. Nessa etapa, a participação de pescadores experientes na atividade foi essencial para localização dos pesqueiros, partindo de uma perspectiva de territorialização definida pelos próprios pescadores. Ainda nesta fase, foi possível compreender as implicações para a atividade como: distância até o pesqueiro, áreas boas/ruins, restritas à pesca.

O primeiro mapeamento foi realizado em Ferreira Gomes, no dia 18 de janeiro de 2019. A pesca atualmente é realizada em um espaço muito restrito, devido às duas hidrelétricas que cercam o município. Esse fator possibilitou a ida in loco para conhecer e mapear as áreas pretendidas.

Para que se conseguisse executar essa proposta, foram necessários um carro estilo caminhonete, uma embarcação da categoria voadeira, motor do tipo popa, um receptor GPS para a coleta dos pontos e uma câmera fotográfica, para registro das imagens (Figura 3).

Figura 3 - Ferreira Gomes (AP): Deslocamento para o mapeamento participativo, 2019.

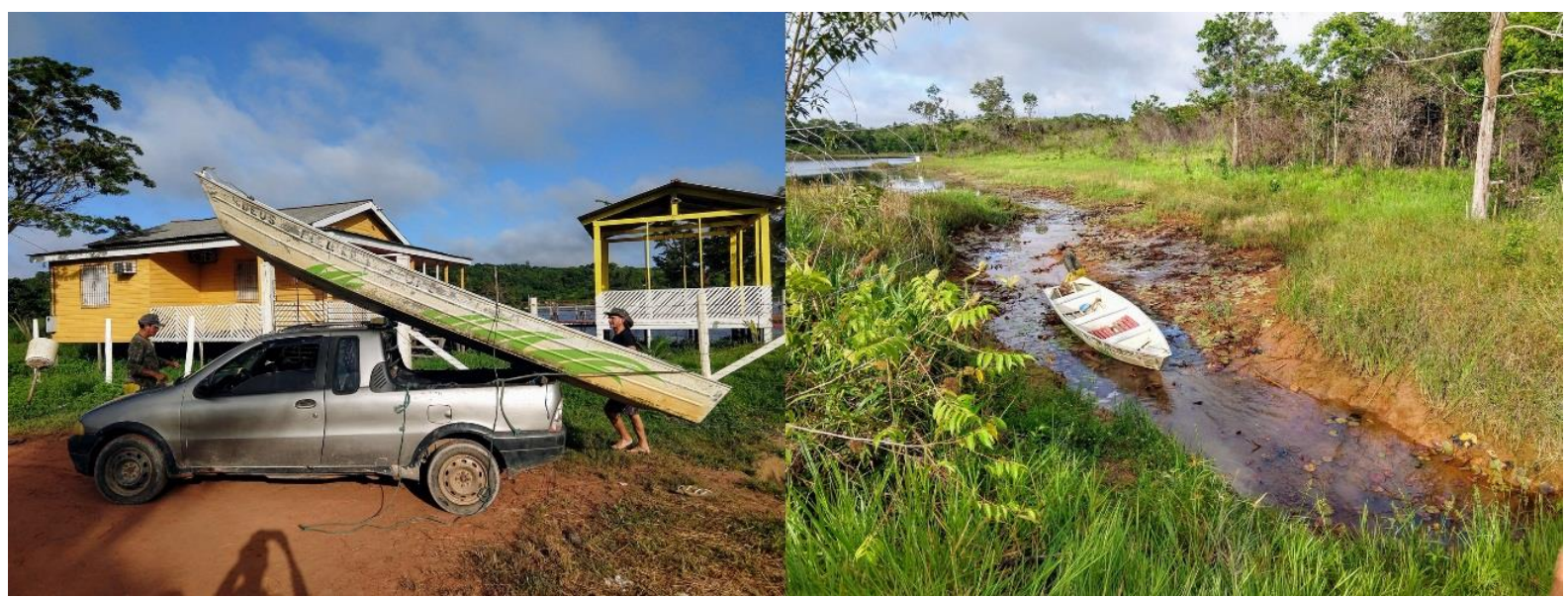

Fonte - Autores (2019).

Para chegar aos locais de pesca, é necessário antes realizar um percurso de carro de $3 \mathrm{~km}$ até o ponto de embarque. $O$ trajeto em água foi de uma distância de $24 \mathrm{~km}$, entre ida e volta, e teve a duração de quatro horas, divididas em observação, marcação de pontos e visita a locais relevantes à atividade como: acampamentos, atracadouro e outras vias de acesso ao lugar de pesca.

\section{Bases, equipamentos e análise de dados}

A pesquisa foi realizada com o apoio das bases digitais cartográficas (quanto aos vetores) do Instituto Brasileiro de Geografia e Estatística (IBGE); da Secretaria de Estado do Meio Ambiente do Amapá (SEMA) e Agencia Nacional de Energia Elétrica (ANEEL), correspondentes aos anos de 2010, 2003 e 2019 respectivamente. As imagens orbitais partiram da Base Cartográfica Digital Contínua do Estado do Amapá (BCDC), disponibilizadas pela SEMA.

$\begin{array}{llllll}\text { Caminhos de Geografia } & \text { Uberlândia-MG } & \text { v. } 21, \text { n. } 77 & \text { Out/2020 } & \text { p. 151-164 Página } 155\end{array}$


Os dados cartográficos foram utilizados inicialmente na construção de mapas, que serviram como agentes de orientação e localização em campo. Foram elaborados mapas bases, constando: limite dos municípios, limite estadual, localidades, estrutura urbana e hidrografia das áreas em estudo, com escala de 1:100000.

A organização dos dados se deu em duas fases: a primeira por meio do editor de planilhas Excel, pertencente ao pacote Office da versão 2010, onde as informações do grupo focal foram organizadas, categorizados e qualificadas. Na segunda etapa, para fins de processamento em ambiente digital dos dados coletados em campo, construção do Banco de Dados Geográfico (BDG) e elaboração dos mapas, foi utilizado o software ArcGis 10.04 .

\section{RESULTADOS E DISCUSSÃO}

\section{A pesca no estado do Amapá: uma aproximação das características da atividade no médio Araguari}

Existe um consenso de que as águas da Amazônia possuem a maior diversidade de peixes de água doce do mundo. Ainda não se sabe com precisão o número de peixes presentes, mas estimativas indicam números entre 1,5 a seis mil espécies. Outros estudos recentes estimam esse número em cerca de três mil, mesmo que dezenas de espécies novas sejam descritas a cada ano e outro tanto seja colocado em sinonímia (SANTOS; SANTOS, 2005).

O Amapá, como parte da Amazônia, carrega todo esse potencial e se destaca como um dos estados mais promissores no que se refere aos recursos pesqueiros (MPA, 2011). Isso se desenha por meio de sua ampla malha hídrica, constituída de 39 bacias hidrográficas, que em conjunto, representam uma área de $82.696 \mathrm{~km}^{2}$, abrangendo os 16 municípios do estado, e que correspondem a aproximadamente $1 \%$ dos cursos hídricos de todo o território nacional (CORRÊA; TOSTES, 2017).

Há de se ressaltar, também, que o estado representa $17 \%$ da plataforma continental da região norte do país, correspondendo a aproximadamente $50.000 \mathrm{~km}^{2}$. Essas qualidades possibilitam condições propícias para a produção de pescado nos mais diversos ambientes aquáticos, sejam eles de águas interiores, estuarinas ou marítimas (SILVA; DIAS, 2010).

É possível apontar, nestes termos, a bacia hidrográfica do Rio Araguari como a mais importante do estado, não somente pela sua abrangência hídrica, mas pelas diversas camadas sócias que durante 0 tempo construíram o seu território nesse espaço (PORTO, 2002; LIMA, 2004).

No médio curso dessa bacia, a atividade de pesca atua como operadora socioeconômica na manutenção das comunidades locais. Entretanto, os novos dilemas, impostos pela chegada dos grandes empreendimentos hidroelétricos, tem colocado em xeque toda uma estrutura organizacional/econômica que se constituiu através dos anos.

Portanto, considerando que a pesca constrói seus arranjos a partir das especificidades ambientais, culturais e econômicas locais, realizar uma caracterização se torna um passo importante para o seu entendimento, bem como das suas dinâmicas.

Munido dos conceitos e definições dispostos anteriormente, com o apoio dos estudos realizados localmente por Oliveira et al. (2018), acerca da pesca artesanal no médio e alto Araguari, e de Morales (2018), que buscou caracterizar a pesca e produção pesqueira em Ferreira Gomes, associados aos conhecimentos adquiridos a partir dos trabalhos de campo, se tornou possível organizar um quadro da pesca no médio Araguari. 
Quadro 3 - Médio Araguari (AP): Características da pesca na área de estudo, 2019.

\begin{tabular}{|c|c|}
\hline \multicolumn{2}{|r|}{ A pesca } \\
\hline Elemento & Característica \\
\hline Petrechos & $\begin{array}{l}\text { Malhadeira; Linha de mão; Zagaia; Espinhel; Caniço; Tarrafa; Trapo; Boia; Arpão; Farol } \\
\text { de pilha; Isca artificial; Rede de cerco e Armadilha. }\end{array}$ \\
\hline Espécies & $\begin{array}{l}\text { Pacu dos tipos: curupeté, cumarú, mafurá, branco e ferro; Mandubé; Branquinha; } \\
\text { Piranha-preta; Trairão; Traira gapó; Aracu-cabeca-gorda; Mandi-fusaca; Uéua com listra; } \\
\text { Uéua; Tucunaré e Sarda. }\end{array}$ \\
\hline Ambientes & Lago; Rio; Igarapé e Reservatório. \\
\hline $\begin{array}{l}\text { Tipo de } \\
\text { embarcação }\end{array}$ & Batelão e Canoa (média de 7 metros). \\
\hline $\begin{array}{l}\text { Número de } \\
\text { pescarias }\end{array}$ & Média de 9 no período chuvoso e 8 no período seco. \\
\hline \multicolumn{2}{|r|}{ O pescador } \\
\hline Idade & Média de 42 anos. \\
\hline Gênero & $57,78 \%$ feminino e $42,22 \%$ masculino. \\
\hline Tempo na pesca & Tempo que varia entre 6 e 40 anos de experiência. \\
\hline Renda mensal & Média de $\mathrm{R} \$ 932,89$. \\
\hline Estado civil & Casados 30,73\%; União estável 42,22\%; Solteiros $25,19 \%$ e Divorciados $2,22 \%$. \\
\hline Escolaridade & $\begin{array}{l}\text { Ens. fundamental incompleto 42,96\%; Ens. médio incompleto 18,52\%; Ens. fundamental } \\
\text { completo 14,07\%; Ens. médio completo 14,07\%; nunca estudou 5,19\%; só assina o nome } \\
4,44 \% \text { e em fase de conclusão de curso superior } 0,74 \% \text {. }\end{array}$ \\
\hline
\end{tabular}

Fonte - Morales (2018); Oliveira et al. (2018) adaptado pelos autores (2019).

Observado os aspectos descritos acima, pode-se afirmar que a pesca na área se enquadra na modalidade artesanal. Isso se dá, essencialmente, pelas características empregadas na atividade, como: os meios utilizados para se capturar o pescado; a estrutura social/familiar de suporte às pescarias; a quantidade de pescado capturado e a destinação do peixe.

Quanto aos meios, a pesca no médio Araguari se constitui por elementos de baixo poder predatório, desenhado nas embarcações de pequeno porte e nos apetrechos de captura que não objetivam a pesca em larga escala. Essa é uma das especificidades que Diegues (1983) aponta para uma atividade de extrato artesanal.

Ainda para o autor, na mesma obra, outra característica importante se constitui na estrutura social/familiar que baseia as pescarias. Na área estudada, ela se dá pelo emprego da força familiar ou da vizinhança, o que também corrobora para a consolidação do enquadramento na modalidade.

A quantidade de pescado capturado na área é baixa quando comparado à pesca em larga escala. No município, existe uma média de $50 \mathrm{~kg}$ de pescado capturado nas pescarias de 1 a 2 dias. Essa média tem caído drasticamente nos últimos anos, o que influencia diretamente na alimentação do pescador, visto que nesses locais o pescado é a principal fonte de proteína e, por consequência, parte central na segurança alimentar.

Esse fator está atrelado à renda do pescador, uma vez que o pescado é utilizado também para fins comerciais. A venda é feita predominantemente de forma direta, em suas próprias residências ou em locais específicos das cidades.

É percebido, então, que essas comunidades, onde a pesca representa uma atividade chave, desenvolveram formas próprias de manejo dos recursos naturais que não visam diretamente o lucro, mas a reprodução social. Todavia, essa lógica tem se alterado em um regime bastante acelerado, devido, principalmente, à implantação das UHE de Ferreira Gomes e Cachoeira Caldeirão na área.

$\begin{array}{lllll}\text { Caminhos de Geografia } \quad \text { Uberlândia-MG } & \text { v. 21, n. } 77 & \text { Out/2020 } & \text { p. 151-164 Página } 157\end{array}$




\section{Territórios fragilizados: as dinâmicas da pesca no médio Araguari pós-instalação das hidroelétricas}

Os pescadores, do médio Araguari, enfrentam dilemas semelhantes que, em suma, partem de uma mesma premissa: a desestruturação de seus territórios pela implantação e operação das hidroelétricas. Esse processo tem se revelado contínuo e, de certa forma, programado, visto a repetição dos impactos e, consequentemente, das dinâmicas produzidas pelos atores locais.

O município de Ferreira Gomes tem, na UHE de Coaracy Nunes, o ponto de partida de uma série de transformações no ambiente físico, o que influenciou diretamente no modo em que o pescador se relacionava com o meio. A inundação de terras para a formação do reservatório impôs uma nova organização para as pescarias, visto o novo ambiente que se formava.

O impacto dessa modificação nos ambientes de pesca em Ferreira Gomes ocasionou principalmente a diminuição ou desaparecimento de espécies antes encontradas ${ }^{1}$. A partir da inserção de uma estrutura do porte de uma hidroelétrica, impactos são gerados em cadeias que se desdobram em todas as dinâmicas da atividade de pesca. No município, o impacto ocasionou principalmente a diminuição ou desaparecimento de espécies antes encontradas; a redução do pescado desencadeou mais pescarias e, consequentemente, um maior custo financeiro para o pescador.

O ambiente que foi modificado pela UHECN se manteve estável por mais de três décadas. A paisagem, que outrora era artificial, se tornou, de certa forma, natural, visto que muitos pescadores que hoje atuam na área só conheceram a realidade da paisagem já transformada.

Essa lógica, tomada por uma visão marxista, onde a natureza do lugar é entendida em dois estados: intocado pela sociedade (primeira natureza) e transformado pela ação humana (segunda natureza), ajuda a entender a percepção do pescador atual sobre o meio.

Esse cenário pode ser compreendido também pela percepção de Santos (2004), o qual explica que o meio natural, ao passar por etapas de artificialização, se torna um meio técnico ou tecnificado, entretanto, isso só ocorre com o surgimento das máquinas. "Estamos porém, reservando a apelação de meio técnico à fase posterior à invenção e ao uso das máquinas, já que estas, unidas ao solo, dão uma nova dimensão à respectiva geografia" (2004, p. 234). Assim, a máquina seria o recorte teórico para o entendimento das mudanças na relação sociedade-natureza, tendo em vista que, a partir delas, houve uma territorialização em forma de rodovias, estradas de ferros e reservatórios artificiais. Suertegaray (2002), ao considerar a ideia de Santos, adota o termo "transfiguração", no sentido em que natureza quando possuída pela sociedade, transfigura-se, adquire uma outra dimensão.

Em um primeiro momento, os processos descritos se afirmam na área. A hidroelétrica, tomada como "máquina", territorializou o espaço e modificou o meio natural às suas necessidades e, dessa forma, o transfigurou em uma nova dimensão. Esse contexto imprimiu ao pescador um novo esforço de adaptação por meio da aprendizagem, seja na procura de novos locais de pesca, na mudança de apetrechos e/ou na organização de ida às pescarias. Os pescadores, em especial os do município de Ferreira Gomes, viveram esse processo na implantação da UHECN e, de certa forma, vivem novamente com a implantação da UHEFG.

As dinâmicas vistas atualmente dão conta de uma atividade executada nos mesmos moldes de antes da implantação da UHEFG, no que se refere, especialmente, às embarcações e apetrechos: os pequenos barcos de madeira, desenhado nas canoas ou nos comumente chamados "batelões", movidos a motor do tipo "rabeta" e/ou a remo, ainda são os responsáveis pelo transporte nas pescarias; e a captura se dá principalmente por meio das redes de emalhar, dos anzóis e, mais recentemente, do arpão.

A manutenção deste modelo pode estar ligada ao processo de construção dos saberes que, nas comunidades locais, atende a um tempo diferente, de caráter profundamente orgânico nas relações com a natureza. Entretanto, é importante ressaltar que existe uma busca por novas tecnologias. Porém, a frágil economia das famílias dificulta o acesso.

${ }^{1}$ Os estudos realizados por Sá-Oliveira et. al. $(2013 ; 2016)$ descrevem parte desse cenário. 
Esta fragilidade advém, primordialmente, da dificuldade de acesso e/ou venda do pescado e se interrelaciona com outros entraves que, além de alto custo financeiro, têm atribuído um esforço cada vez maior por parte dos pescadores para a execução da atividade.

A pesca em Ferreira Gomes tem, no reservatório da UHEFG um meio central na atividade, tanto no ambiente explorado nas pescarias, quanto no acesso a outros corpos d'agua (Figura 4).

Figura 4 - Ferreira Gomes (AP): Lago artificial da Hidroelétrica Ferreira Gomes, 2019.

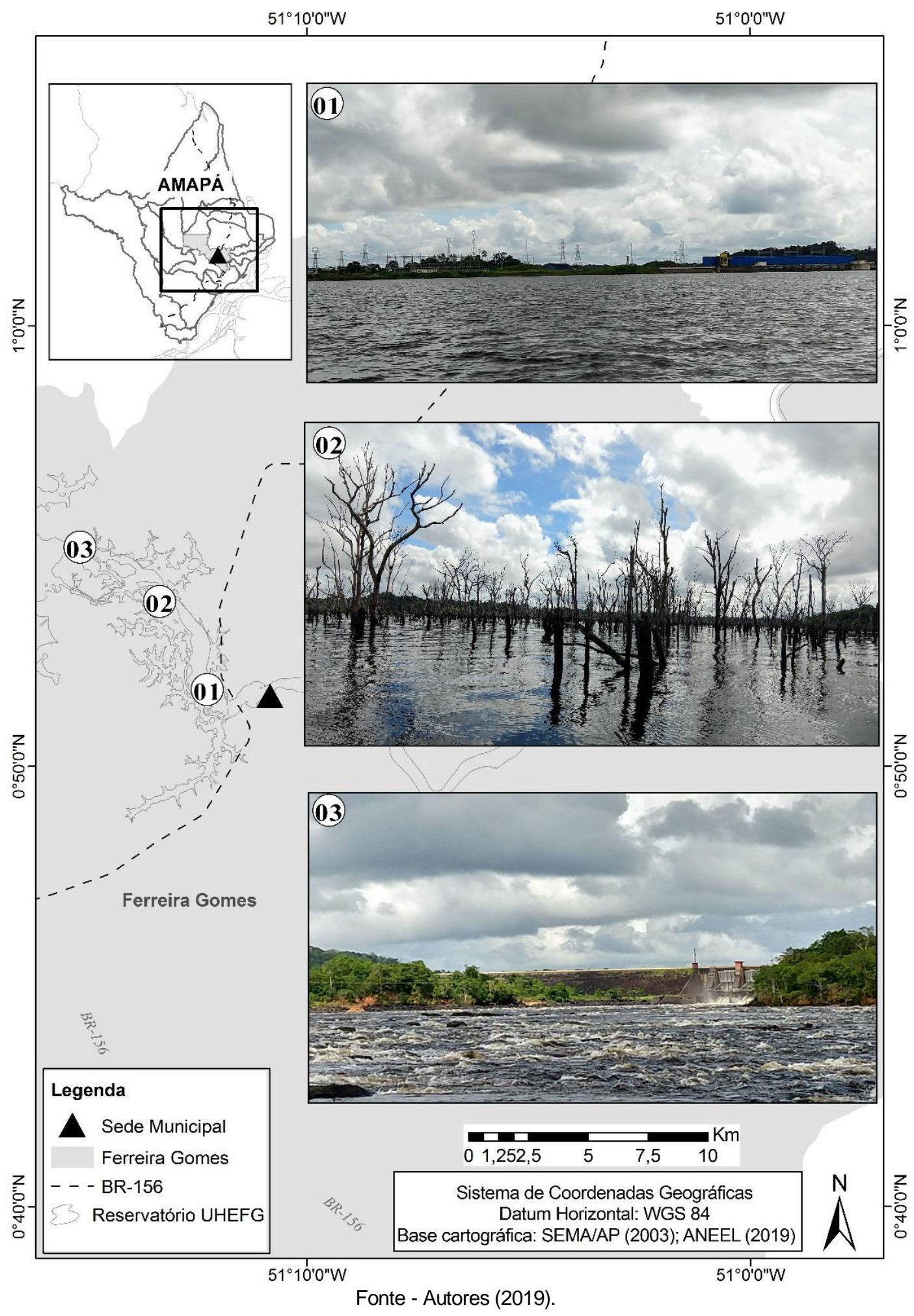

v. 21, n. 77

Out/2020

p. 151-164

Página 159 
Para se chegar até o ponto de embarque, é necessário a utilização de um carro para transportar a embarcação. Essa dinâmica tem demandado um custo financeiro adicional aos pescadores, com isso, aumentando em mais de $100 \%$ o custo para as pescarias.

Atualmente, em média, o pescador gasta 200 reais para pescarias de até dois dias. Esse montante é dividido entre: aluguel do automóvel (a grande maioria não possui carro próprio); compra de combustível para a embarcação; gelo para a conservação do pescado e alimentos básicos como farinha de mandioca e sal.

$\mathrm{Na}$ água, a busca pelo peixe não se dá de maneira aleatória ou ao acaso. Begossi (2004) explica que o pescado, em geral, é encontrado agregado em manchas, denominados de pesqueiros. Esses pontos são reconhecidos pelos pescadores por referências aquáticas ou terrestres.

No ambiente em questão, os principais pontos das pescarias estão nos chamados poços ${ }^{2}$, presentes no reservatório. Também existem zonas importantes nos igarapés e corredeiras adjacentes, a figura 5 ilustra a disposição espacial dos pontos e os classifica quanto ao seu nível de pesca.

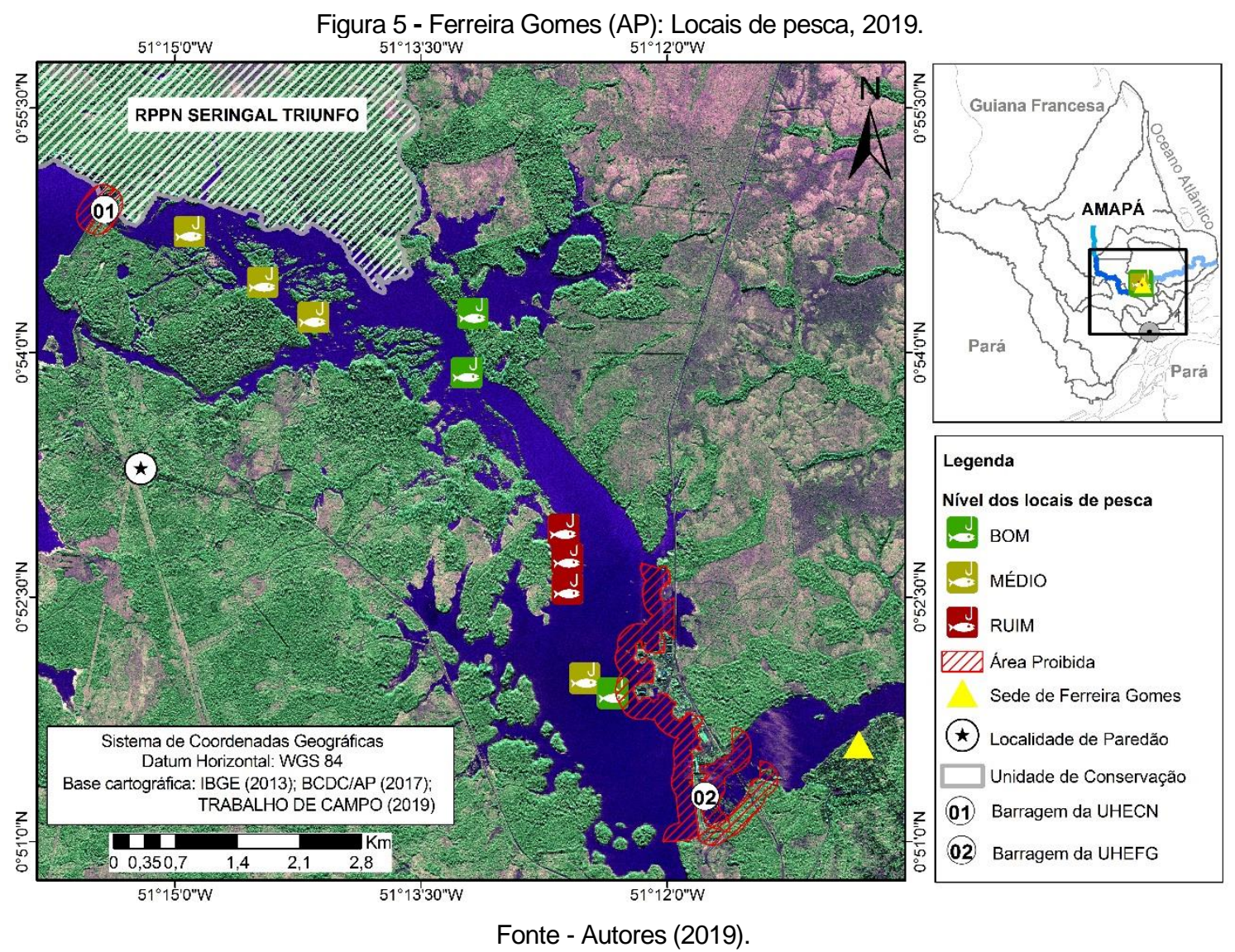

Os pesqueiros ilustrados no mapa são anteriores a implantação da UHEFG. Neles, o nível de pesca era considerado excelente, tanto pela quantidade de pescado encontrado, quanto pelas espécies de alto valor comercial, como: Pescada Branca (Cynoscion Leiarchus), Pescada Amarela (Cynoscion acoupa), curupeté (Piaractus Mesopotamicus) e trairão (Hoplias spp).

Em pescarias de 3 a 4 dias, se conseguia em média 150kg de pescado. No momento atual, o nível diminuiu de maneira homogênea para todas as espécies, abreviando a média para $50 \mathrm{~kg}$ por pescaria. A perda de biomassa pesqueira pode ser explicada, segundo Sá-Oliveira et al. (2015), pelas modificações ambientais presentes nos reservatórios, que estão ligadas a fatores ambientais, como profundidade, nível do reservatório e clareza da água.

${ }^{2}$ Segundo Oliveira et. al (2018) os poços são áreas com maior profundidade do leito do rio, e, menor correnteza.

$\begin{array}{llllll}\text { Caminhos de Geografia } & \text { Uberlândia-MG } & \text { v. } 21, \text { n. } 77 & \text { Out/2020 } & \text { p. 151-164 Página } 160\end{array}$


Outro indicador que pode ser apontado a respeito da queda na captura do pescado, é o aumento de pescadores explorando os mesmos espaços, atraídos pela "facilidade" da pesca em águas menos movimentadas, como as dos reservatórios. Esse adensamento tem causado tensões territoriais, mas que, de maneira geral, não evoluem para conflitos efetivos.

Assim, existem duas configurações territoriais claras nesse contexto: a primeira diz respeito ao território dos pescadores, construído de forma orgânica através dos anos; a outra, a das hidroelétricas, fixada pelo capital no espaço de maneira artificial, intermediada pelo Estado. Contudo, o modo e a disposição espacial em que essas estruturas foram instaladas, fragilizaram os territórios preexistentes, como também dificultou os atores na busca por novos espaços.

Atualmente, a atividade de pesca é realizada em pouco mais de $13 \mathrm{~km}^{2}$, limitada, principalmente, pela área física ocupada pelas hidroelétricas, bem como pela proibição da atividade em áreas próximas a montante e a jusante da barragem.

Foi observado que os limites impostos pelas hidroelétricas têm sido ultrapassados pelos pescadores. Esse movimento, mais do que uma forma de ter acesso a outros espaços de pesca, remete a uma autoafirmação de poder e controle territorial perante tanto ao Estado, quanto ao empreendimento. Essa ação tem gerado uma série de conflitos entre os pescadores e os representantes das hidroelétricas, em especial os da UHEFG. O resultado desses embates, na maioria das vezes, tem o pescador como mais afetado, uma vez que quando flagrados, seus apetrechos e embarcações são apreendidos.

Assim o médio Araguari como é visto hoje, é fruto dessas atividades que se apropriaram do seu recurso e, por meio disso, construíram seus territórios. A pesca é um desses agentes tem realizado esse movimento de forma orgânica, visando essencialmente a reprodução e manutenção social.

\section{CONSIDERAÇÕES FINAIS}

As UHE presentes no município de Ferreira Gomes, indiscutivelmente, produziram fortes impactos físico-ambientais e sociais nos espaços onde foram instaladas. Isso se deu, especialmente, pelo processo impositivo de apropriação do Rio Araguari por esses empreendimentos. Esse movimento impôs as comunidades de pescadores artesanais da região um novo contexto, onde recurso hídrico agora necessitava ser compartilhado de maneira diferente.

A criação do reservatório por meio da artificialização de parte do leito do rio, obrigou o pescador a produzir e/ou adaptar as estratégias de pescarias realizadas há décadas, construídas por meio do conhecimento tradicional coletivo, para esse novo ambiente.

O caso de Ferreira Gomes é particular, pois grande parte dos pescadores só conheceu o ambiente modificado pela UHECN, o que denota uma percepção naturalizada para a pesca no reservatório. Entretanto, com a chegada das UHEFG e UHECC esse contexto foi modificado. Os pescadores do município hoje se encontram cercados pelos reservatórios dos empreendimentos, o que dificulta a ida em locais mais distantes, onde existam diferentes ambientes, dado o caráter da atividade realizada.

Foi identificado que o nível de pesca caiu drasticamente para todas as espécies, afetando diretamente a renda familiar do pescador. A estratégia encontrada para complementação da renda se deu pela realização de outras atividades como a agricultura e o extrativismo. As novas dinâmicas de organização e uso do território buscadas pelos pescadores visando barrar deterioração contínua dos seus meios de vida

A figura do Estado nesse contexto, tem se mostrado permissiva aos danos deixados e inoperante quanto à fiscalização dos problemas produzidos pela operação dos empreendimentos. Se tornou comum problemas relacionados a mortandade de peixes e inundações. Esses problemas poderiam ser resolvidos ou mesmo minimizados se houvesse uma maior participação dos pescadores na tomada de decisões em todas as etapas de implantação das estruturas.

\section{AGRADECIMENTOS}

Agradecemos a Coordenação de Aperfeiçoamento de Pessoal de Nível Superior (CAPES) e a Fundação de Amparo à Pesquisa do Amapá (FAPEAP) pela bolsa de pesquisa de mestrado concedida para a realização deste trabalho. Somos gratos também os pescadores do Médio Araguari, pelo acolhimento durante o estudo e pela resistência diante das novas dinâmicas impostas. 


\section{REFERÊNCIAS}

ANEEL. Energia Hidráulica. 2008. Disponível em: <https://bit.ly/2vzF5gP>. Acesso em: 16 set. 2019.

BEGOSSI, A. Áreas, pontos de pesca, pesqueiros e territórios na pesca artesanal. In: BEGOSSI, A. (Org.). Ecologia de pescadores da Mata Atlântica e da Amazônia. São Paulo: HUCITEC, 2004.

BERMANN, C. Impasses e controvérsias da hidroeletricidade. Estudos Avançados, v. 21, n. 59, p. 139-153, abr. 2007. Disponível em: <https://bit.ly/37Ftl4S>. Acesso em: 11 out. 2017. https://doi.org/10.1590/S0103-40142007000100011

CAMPOS, K. F. S. Novas dinâmicas territoriais da Usina Hidrelétrica de Santo Antônio, no Vale do Jari: a desconstrução do uso do território e de produtos na RDS do Iratapuru - AP. 2016. 107 f. Dissertação (Mestrado em Desenvolvimento Regional) - Universidade Federal do Amapá, Macapá, 2016.

CHAVES, C. M. S. R. S. Mapeamento participativo da pesca artesanal na Baía de Guanabara. 2011. 187 f. Dissertação (Mestrado em Geografia) - Universidade Federal do Rio de Janeiro, Rio de Janeiro, 2011.

CORREA, K. A; PORTO, L. R. Os empreendimentos hidrelétricos no rio Araguari e seus efeitos no espaço urbano amapaense. In: XVII ENANPUR: Desenvolvimento, crise e resistência: quais os caminhos do planejamento urbano e regional? São Paulo, 2017. Anais [...] São Paulo: ENANPUR, 2017. p. 01-18.

CRUZ NETO, O. O trabalho de campo como descoberta e criação. In: MINAYO, M. C. S. (Org.). Pesquisa social: teoria, método e criatividade. 7. ed. Petrópolis: Vozes, 1994. p. 51-66.

DA SILVA, C. N. Cartografia das percepções ambientais-territoriais dos pescadores do estuário amazônico com utilização de instrumentos de geoinformação. Formação (Online), v. 01, n. 15, 2008. Disponível em: <https://bit.ly/36yhYzW>. Acesso em: 03 set. 2018.

DE FRANCESCO, A. CARNEIRO, C. (Eds.). Atlas dos Impactos da UHE Belo Monte sobre a pesca. São Paulo: Instituto Socioambiental (ISA), 2015.

DEBUS, M. Manual para excelencia em la investigación mediante grupos focales. Washington: Academy for Educational Development, 1997.

DIEGUES, A. C. A interdisciplinaridade nos estudos do mar: o papel das Ciências Sociais. In: XV Semana de Oceanografia. São Paulo, 2003. Anais [...]. São Paulo: Instituto Oceanográfico da USP, 2003. p. 01-23. Disponível em: <https://bit.ly/2O9XZkB>. Acesso em: 02 jan. 2017.

A pesca construindo sociedades: leituras em antropologia marítima e pesqueira. São Paulo: Núcleo de Apoio à Pesquisa sobre Populações Humanas e Áreas Úmidas Brasileiras/USP, 2004.

Pescadores, camponeses e trabalhadores do mar. São Paulo: Ática, 1983.

GONDIM, S. M. G. Grupos focais como técnica de investigação qualitativa: desafios metodológicos. Paidéia, v. 12, n. 24, p. 149-161. 2003. Disponível em: <https://bit.ly/2tSvLUV>. Acesso em: 03 set. 2018. https://doi.org/10.1590/S0103-863X2002000300004

IBAMA. Estatística da pesca: grandes regiões e unidades da federação. Brasília: IBAMA, 2007.

JUNK, W. J; MELLO, J. A. S. N. Impactos ecológicos das represas hidrelétricas na bacia amazônica brasileira. Estudos Avançados, v. 04, n.0 8, p. 126-143, abr. 1990. Disponível em: <https://bit.ly/37zF4rc>. Acesso em: 14 mar. 2018. https://doi.org/10.1590/S0103$\underline{40141990000100010}$ 
LIMA, R. A. P. Antropizacion, dinámicas de ocupación del territorio y desarrollo en la Amazonía Brasileña: el caso del estado de Amapá. 2004. 80 f. Tese (Doutorado em Geografia) - Universitat Autònoma de Barcelona (UAB), Barcelona, 2004.

MINAYO, M. C. S (Org.). Pesquisa Social: teoria, método e criatividade. 18. ed. Petrópolis: Vozes, 2001.

O Desafio do conhecimento: pesquisa qualitativa em saúde. São Paulo/Rio de Janeiro: HUCITEC/ABRASCO, 1992.

MORALES, U. S. Caracterização da pesca e produção pesqueira no Médio Araguari, Ferreira Gomes, Amapá, Brasil. 2018. 96 f. Dissertação (Mestrado em Desenvolvimento Regional) - Universidade Federal do Amapá, Macapá, 2018.

MPA. Ministério da Pesca e Aquicultura. Mais Pesca e Aquicultura: políticas para o desenvolvimento da aquicultura brasileira. Brasília: MPA, 2011.

OLIVEIRA, J. C. S.; et al. Caracterização da pesca no reservatório e áreas adjacentes da UHE Coaracy Nunes, Ferreira Gomes, Amapá - Brasil. Biota Amazônia, Macapá, v. 03, n. 03, p. 83-96, dez. 2013. Disponível em: <https://bit.ly/38Mv26n>. Acesso em: 02 fev. 2018. https://doi.org/10.18561/2179-5746/biotaamazonia.v3n3p83-96

OLIVEIRA, N. S.; et al. A pesca artesanal no Alto e Médio Rio Araguari, Amapá, Brasil. Holos, ano 34, v. 08, p. 81-98, dez. 2018. Disponível em: <https://bit.ly/2O7FWMc>. Acesso em: 18 fev. 2018. https://doi.org/10.15628/holos.2018.6820

PINTO, L. F. Hidrelétricas na Amazônia: predestinação, fatalidade ou engodo? Belém: Edição Jornal Pessoa, 2002.

PORTO, J. L. R. Amapá: principais transformações econômicas e institucionais (1943-2000). 2002. 206 f. Tese (Doutorado em Economia) - Universidade Estadual de Campinas, Instituto de Economia, Campinas, 2002.

PROVAM. Programa de Estudos e Pesquisas nos Vales Amazônicos. Belém: PROVAM, 1990.

SANTOS, G. M. Impactos da Hidrelétrica Samuel sobre as comunidades de peixes do rio Jamari (Rondônia, Brasil). Acta amazônica, Manaus, v. 25, n. 03-04, p. 247-280, 1995. Disponível em: <https://bit.ly/37Ek8zh>. Acesso em: 24 abr. 2018. https://doi.org/10.1590/1809-43921995253280

SANTOS, A. C. M. Sustentabilidade da pesca na Amazônia. Estudos Avançados, v. 19, n. 54, p. 165-182, ago. 2005. Disponível em: <https://bit.ly/2OagaqG>. Acesso em: 02 abr. 2018. https://doi.org/10.1590/S0103-40142005000200010

SANTOS, M. A natureza do espaço. 4. ed. São Paulo: Edusp, 2004.

SÁ-OLIVEIRA, J. C.; et al. Factors structuring the fish community in the area of the Coaracy Nunes Hydroelectric reservoir in Amapá, Northern Brazil. Tropical Conservation Science, v. 09, n. 01, p. 1633, mar. 2016. Disponível em: <https://bit.ly/2uGtVX4>. Acesso em: 18 dez. 2018. https://doi.org/10.1177/194008291600900103

SILVA, L. M. A.; DIAS, M. T. A pesca artesanal no estado do Amapá: estado atual e desafios. Boletim Técnico Científico do CEPNOR, v. 10, n. 01, p. 43-53. 2010. Disponível em: <https://bit.ly/38R96ad>. Acesso em: 20 abr. 2018. https://doi.org/10.17080/1676-5664/btcc.v10n1p43-53

SOUSA, W. L. Impacto ambiental de hidrelétricas: uma análise comparativa de duas abordagens. Arthropod Structure \& Development, v. 39, n. 02-03, p. 01-160. 2000.

$\begin{array}{llllll}\text { Caminhos de Geografia } & \text { Uberlândia-MG } & \text { v. } 21, \text { n. } 77 & \text { Out/2020 } & \text { p. 151-164 Página } 163\end{array}$


SUERTEGARAY, D. M. A. Geografia Física (?) Geografia Ambiental (?) ou Geografia e Ambiente (?). In: MENDONÇA, F.; KOZEL, S. (Org.). Epistemologia da Geografia Contemporânea. Curitiba: UFPR, 2002. p. 111-120.

SZTUTMAN, M. Etnomapeamento: uma técnica robusta, barata e de fácil implementação para a gestão etnoambiental em Terras Indígenas. Manaus: The Nature Conservancy, 2006. Disponível em: <http://www.ibcperu.org/doc/isis/6409.pdf>. Acesso em: 16 mar. 2018.

Recebido em: 01/02/2020

Aceito para publicação em: 18/08/2020 